\title{
Lack of association between MDM2 SNP309 and TP53 Arg72Pro polymorphisms with clinical outcomes in myelodysplastic syndrome
}

\author{
J. A. MACHADO-NETO ${ }^{\ddagger}$, F. TRAINA ${ }^{\ddagger}$, P. DE MELO CAMPOS, M. F. ANDREOLI-RISSO, F. F. COSTA, S. T. OLALLA SAAD*
}

Hematology and Hemotherapy Center - University of Campinas / Hemocentro-Unicamp, Instituto Nacional de Ciencia e Tecnologia do Sangue, Campinas, Sao Paulo, Brazil

${ }^{*}$ Correspondence: sara@unicamp.br

${ }^{\ddagger}$ Contributed equally to this work.

Received January 27, 2012 / Accepted March 27, 2012

\begin{abstract}
$\mathrm{MDM} 2 / \mathrm{p} 53$ pathway plays an important role in the control of apoptotic and proliferation mechanisms, and alterations in this pathway have been described in myelodysplastic syndromes (MDS). We investigated the frequency of MDM2 SNP309, TP53 Arg72Pro polymorphisms in de novo MDS and the association of these polymorphisms with clinical characteristics. Our results showed that the frequencies of genotypes for MDM2 SNP309 and TP53 Arg72Pro did not differ between MDS and healthy controls and that these polymorphisms were not associated with clinical and laboratory parameters, disease progression and overall survival, suggesting that MDM2 and TP53 polymorphisms are not involved in risk for MDS, or in the clinical and laboratory characteristics of the disease.
\end{abstract}

Key words: myelodysplastic syndromes, MDM2, TP53, p53, polymorphism

Abnormalities in p53 and its negative regulator, Mouse double-minute (MDM2) play a major role in cancer [1]. The p53 is a transcription factor encoded by TP53 gene that mediates cellular responses to DNA damage by regulating cell-cycle arrest, senescence and apoptosis [2]. MDM2 is an ubiquitin E3 ligase that regulates the stability of p53 [2]. Single nucleotide polymorphisms (SNP) in MDM2 and TP53 have been identified and have been proposed to affect tumorigenecity [3]. The change of $\mathrm{G}$ to the $\mathrm{T}$ allele in the nucleotide 309 (SNP309, rs2279744) of the MDM2 gene results in a higher affinity for Sp1, hence leading to enhanced MDM2 transcription [3]. Higher MDM2 levels can attenuate p53 response [4], which may lead to insufficient DNA repair, reduced apoptosis and tumor formation [5]. A SNP in the codon 72 of the TP53 gene results in either a $C$ or $G$ nucleotide and leads to either a Proline (Pro) or Arginine (Arg) residue at codon 72, respectively (Arg72Pro, rs 1042522) [1,3,6]. The Arg variant has been shown to be more potent in apoptosis induction $[1,6]$ and the Pro variant has been shown to be better for inducing cell-cycle arrest and in its ability to repair damage DNA [3].

Myelodysplastic syndromes (MDS) encompass a heterogeneous group of clonal hematopoietic stem cell disorders characterized by morphological dysplasia, impaired dif- ferentiation and defective cellular functions, resulting in peripheral cytopenias and has a tendency to progress towards acute myeloid leukemia (AML) [7]. Genetic abnormalities in TP53 have been reported in MDS and may be involved in disease progression $[8,9]$. As far as we know, no study has yet investigated the role of MDM2 SNP309 and TP53 Arg72Pro in de novo MDS. Thus, the aim of the present study was to investigate the incidence of MDM2 SNP309 and TP53 Arg72Pro polymorphisms in MDS patients and to correlate the frequency of these polymorphisms with age, neutrophils and platelets at diagnosis, low risk versus high risk disease according to FAB, IPSS, cytogenetic risk, disease progression and overall survival.

\section{Patients and methods}

Subjects. One hundred-three controls and seventy-seven patients with a diagnosis of de novo MDS were included in the study. The diagnosis of MDS was based on bone marrow morphology, including bone marrow aspirate and biopsy, cytogenetics and exclusion of systemic disease. Karyotypes were analyzed by conventional G-banding of bone marrow cells. Twenty metaphases were then analyzed and karyotyped 
in accordance with ISCN (2009) criteria[10]. Patients' characteristics are described in Table 1 . The control group consisted of healthy volunteers; mean age 37 (17-89). All healthy volunteers and patients provided informed written consent and the study was approved by the ethics committee of the University of Campinas.

SNP genotyping. Genomic DNA samples were obtained from peripheral blood samples using phenol-chlorophorm extraction. Identification of MDM2 and TP53 polymorphisms was performed using the polymerase chain reaction and restriction fragment length polymorphism methods as previously described $[3,11]$. In brief, PCR was performed in a $50 \mathrm{uL}$ reaction volume consisting of $100 \mathrm{ng}$ genomic DNA, 5uL reaction buffer 10X, $2 \mathrm{uL} \mathrm{MgCl} 50 \mathrm{mM}, 2.5$ unit of Taq polimerase and $200 \mathrm{nM}$ of each forward and reverse primers. Primers sequences and annealing temperatures are described in Table 2. For RFLP analyses, MDM2 and TP53 PCR products were MspA1I (New England Biolabs, Hitchin, UK) or BstUI (MBI Fermentas, St. Leon-Rot, Germany) digested, according to the manufacturer's protocol, and visualized on 3 or $1 \%$ agarose gel, respectively. The normal genotype for MDM2 was verified by a $157 \mathrm{bp}$ fragment, the heterozygous genotype was verified by 157,146 and $11 \mathrm{bp}$ fragments, whereas homozygous polymorphic genotype demonstrated 146 and $11 \mathrm{bp}$ fragments (Figure 1A-B). For TP53, the polymorphic genotype was verified by 839 bp fragment, the heterozygous genotype was verified by 839,572 and $267 \mathrm{bp}$ fragments, whereas homozygous normal genotype was demonstrated by 572 and $267 \mathrm{bp}$ fragments (Figure 1C-D).

Statistical analysis. Statistical analyses were performed using R Foundation for Statistical Computing, version 2.10.1 (ISBN 3-900051-07-0). The Hardy-Weinberg equilibrium of MDM2 SNP309 and TP53 Arg72Pro was tested by Fisher's exact test. Fisher's exact test or Chi-square $\left(X^{2}\right)$ test were employed to determine the significance of differences in genotypes between patients and controls or in between patient groups. Comparison of median age at diagnosis between patients and different genotypes was carried out using Kruskal-Wallis test. The correlation of genotypes and neutrophils, platelets and bone marrow blast at diagnosis was analyzed by the Wilcoxon rank sum test or Kruskal-Wallis test. Cox regression was applied to evaluate the possible association between the genotypes with disease progression and overall survival. All analyses were performed for MDM2 SNP309, TP53 Arg72Pro and for both polymorphisms in combination. The frequency of $\mathrm{G}$ allele for $M D M 2$ and Pro allele for TP53 were analyzed. A $P$-value $<0.05$ was considered statistically significant.

\section{Results}

To evaluate whether MDM2 and TP53 polymorphisms were associated with a predisposition to de novo MDS, we tested these polymorphisms in 77 patients with MDS and in 103 healthy volunteers (control). The control population was in Hardy-Weinberg equilibrium for MDM2 SNP309 $\left(x^{2}=2.59, P=0.27\right)$ and TP53 Arg72Pro $\left(x^{2}=0.677, P=0.72\right)$ polymorphisms. To determine whether there were significant differences in the distribution of MDM2 and TP53 polymorphisms, we used the T/T genotype for MDM2 SNP309 and the Arg/Arg genotype for TP53 Arg72Pro as reference for analyses and no differences were found (Table 3 ).

In our study, no association was found between MDM2 SNP309 and TP53 Arg72Pro and clinical parameters. Frequencies of MDM2 SNP309 and TP53 Arg72Pro distributed in female and male patient groups were not statistically different $(P=0.156, P=1.000$; respectively and $P=0.516$ for MDM2 and TP53 interaction), indicating that both polymorphisms may not affect MDS susceptibility in a gender-specific manner. We also found no meaningful difference in initial platelet and neutrophil counts and

Table 1. Patients characteristics.

\begin{tabular}{lc}
\hline & $\begin{array}{c}\text { Number of } \\
\text { individuals }\end{array}$ \\
\hline MDS Patients & 77 \\
$\quad$ Age (years), Median (range): 63, (21-89) & \\
Follow-up (month), Median (range): 36, (2-166) & 16 \\
$\quad$ Number of patients that progressed & \\
Time to progression (month), Median (range):10 (2-92) & \\
FAB & $49 / 12$ \\
RA/RARS & $11 / 3$ \\
RAEB/RAEBt & 2 \\
CMML & $31 / 30$ \\
IPSS & $7 / 4$ \\
$\quad$ Low risk/ Intermediate-1 & 5 \\
Intermediate-2/high risk & 60 \\
$\quad$ Not available & $6 / 7$ \\
Cytogenetics & 4 \\
$\quad$ Low risk & \\
Intermediate/high risk & \\
$\quad$ Not available & \\
\hline Abbreviations. FAB: French-American-British; RA: Refractory Anemia; \\
RARS: Refractory Anemia with Ringed Sideroblasts; RAEB: Refractory \\
Anemia with Excess of Blasts; RAEBt: Refractory Anemia with Excess of \\
Blasts in transformation; CMML: Chronic Myelomonocytic Leukemia; IPSS: \\
International Prognostic Scoring System.
\end{tabular}

Table 2. Primer sequences, restriction enzymes and annealing temperatures

\begin{tabular}{cclcc}
\hline Gene & Polymorphisms & Primers Sequences & Restriction Enzyme & Annealing temperature \\
\hline \multirow{2}{*}{ MDM2 } & SNP309 & $\begin{array}{l}\text { F: 5'-CGCGGGAGTTCAGGGTAAAG-3' } \\
\text { R: 5’-CTGAGTCAACCTGCCCACTG-3' }\end{array}$ & MspA1I & $63^{\circ} \mathrm{C}$ \\
\hline \multirow{2}{*}{ TP53 } & Arg72Pro & $\begin{array}{l}\text { F: 5'-TCAGACACTGGCATGGTGTT-3' } \\
\text { R:5'-AAGCCAAAGGGTGAAGAGGA -3' }\end{array}$ & BstUI & $55^{\circ} \mathrm{C}$ \\
\hline
\end{tabular}


A
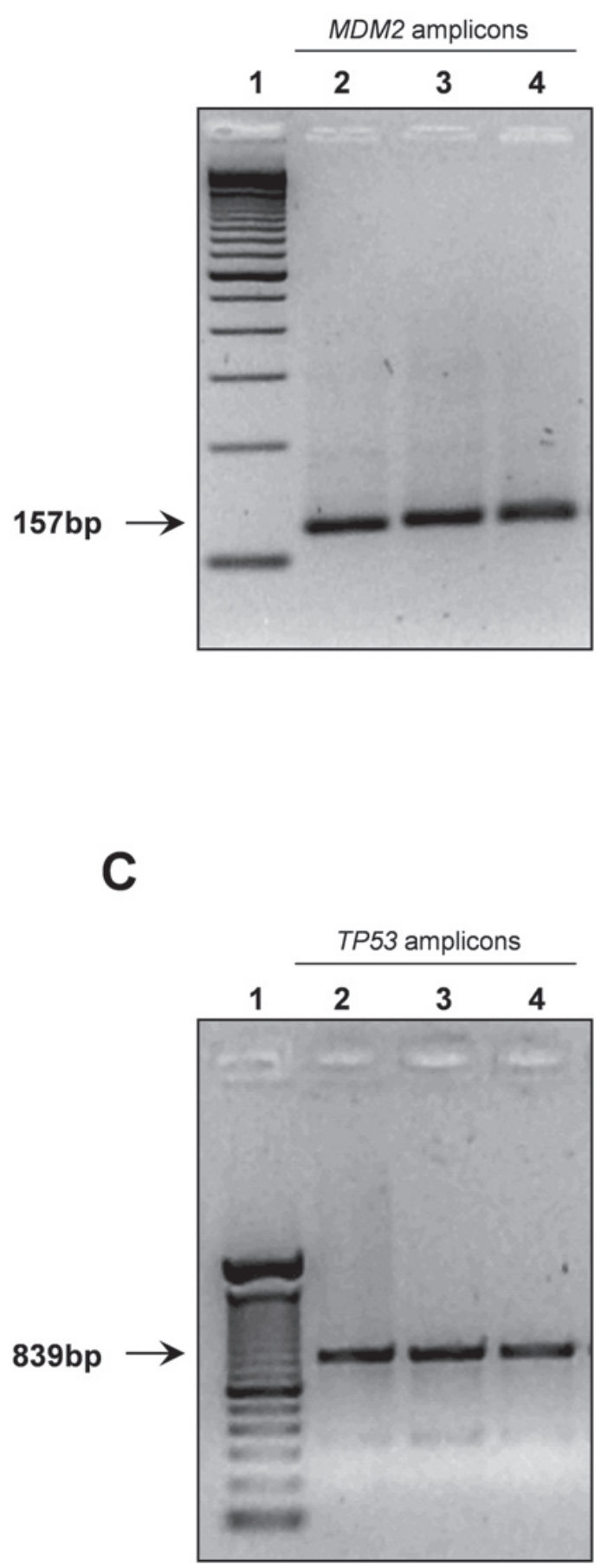

B



D

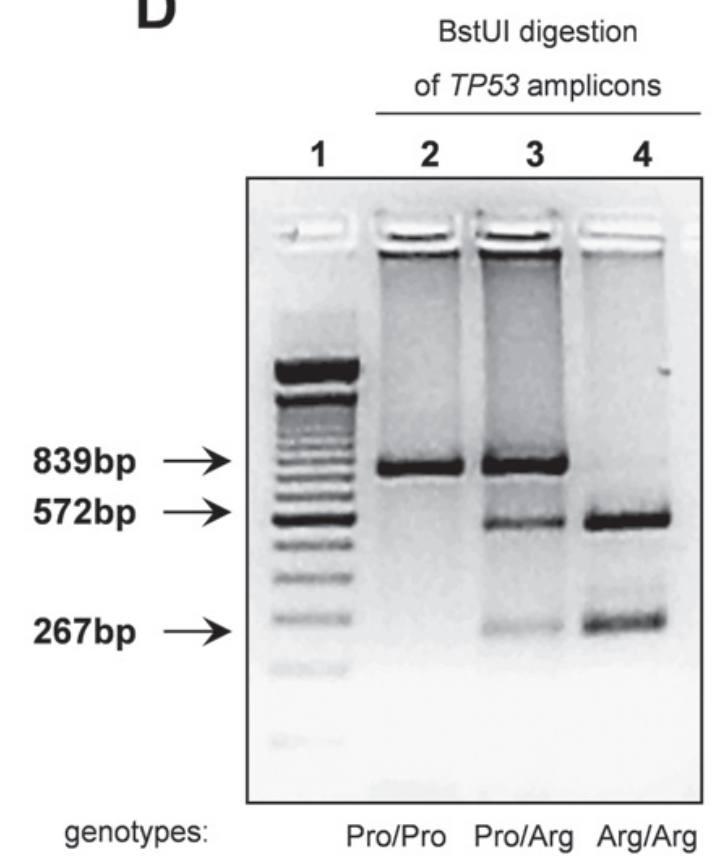

Figure 1. MDM2 SNP309 and TP53 Arg72Pro genotyping. (A) PCR amplification of MDM2: lane 1: Ladder 100bp fragments; lane 2 to 4: 157 bp amplicons obtained from genomic DNA of MDS patients. (B) MspA1I digestion of MDM2 amplicons: lane 1: Ladder 100bp fragments, lane 2: digestion pattern observed in subjects with $T / G$ genotype, lane 3: digestion pattern observed in subjects with $\mathrm{G} / \mathrm{G}$ genotype and lane 4: digestion pattern observed in subjects with T/T genotype. (C) PCR amplification of TP53: lane 1: Ladder 100bp fragments; lane 2 to 4: 839 bp amplicons obtained from genomic DNA of MDS patients. (D) BstUI digestion of TP53 amplicons: lane 1: Ladder 100bp fragments, lane 2: digestion pattern observed in subjects with Pro/Pro genotype, lane 3: digestion pattern observed in subjects with Pro/Arg genotype and lane 4: digestion pattern observed in subjects with Arg/Arg genotype. The fragments sizes are indicated in the figure. 
Table 3. Distribution of allele frequencies of $M D M 2$ and TP53 polymorphisms or their interaction in MDS patients and controls.

\begin{tabular}{|c|c|c|c|c|c|}
\hline \multicolumn{2}{|l|}{ Genotypes } & \multirow[t]{2}{*}{ Controls (n=103), $n^{0}(\%)$} & \multirow[t]{2}{*}{ MDS cases $(n=77), n^{0}(\%)$} & \multirow[t]{2}{*}{ OR $(95 \% \mathrm{CI})$} & \multirow[t]{2}{*}{$P^{*}$} \\
\hline MDM2 SNP309 & TP53 Arg72Pro & & & & \\
\hline $\mathrm{T} / \mathrm{T}$ & & $55(53.4)$ & $40(51.9)$ & 1.00 ref. & \\
\hline $\mathrm{T} / \mathrm{G}$ & & $33(32.0)$ & $30(39.0)$ & $1.25(0.66-2.37)$ & 0.603 \\
\hline $\mathrm{G} / \mathrm{G}$ & & $15(14.6)$ & $7(9.1)$ & $0.64(0.24-1.71)$ & 0.518 \\
\hline \multirow[t]{5}{*}{ G alelle } & & $48(46.6)$ & $37(48.1)$ & $1.06(0.59-1.91)$ & 0.966 \\
\hline & Arg/Arg & $46(44.6)$ & $35(45.4)$ & 1.00 ref. & \\
\hline & Arg/Pro & $42(40.8)$ & $36(46.8)$ & $1.12(0.60-2.10)$ & 0.831 \\
\hline & Pro/Pro & $15(14.6)$ & $6(7.8)$ & $0.53(0.19-1.49)$ & 0.332 \\
\hline & Pro alelle & $57(55.4)$ & $42(54.6)$ & $0.96(0.54-1.75)$ & 0.916 \\
\hline \multirow[t]{3}{*}{$\mathrm{T} / \mathrm{T}$} & Arg/Arg & $19(18.4)$ & $19(24.7)$ & 1.00 ref. & \\
\hline & Arg/Pro & $28(27.2)$ & $18(23.3)$ & $0.64(0.27-1.53)$ & 0.379 \\
\hline & Pro/Pro & $8(7.8)$ & $3(3.9)$ & $0.37(0.09-1.63)$ & 0.302 \\
\hline \multirow[t]{3}{*}{$\mathrm{T} / \mathrm{G}$} & Arg/Arg & $18(17.5)$ & $14(18.2)$ & $0.78(0.30-2.00)$ & 0.637 \\
\hline & Arg/Pro & $11(10.7)$ & $13(16.9)$ & $1.18(0.42-3.29)$ & 0.798 \\
\hline & Pro/Pro & $4(3.9)$ & $3(3.9)$ & $0.75(0.15-3.82)$ & 1.000 \\
\hline \multirow[t]{3}{*}{ G/G } & Arg/Arg & $9(8.7)$ & $2(2.6)$ & $0.22(0.04-1.17)$ & 0.087 \\
\hline & Arg/Pro & $3(2.9)$ & $5(6.5)$ & $1.67(0.35-7.98)$ & 0.702 \\
\hline & Pro/Pro & $3(2.9)$ & $0(0.0)$ & $0.14(0.01-2.96)$ & 0.235 \\
\hline
\end{tabular}

Abbreviations. OR: Odds ratio. ${ }^{*}$ Chi-square test

percentage of bone marrow blasts depending on MDM2 SNP309 or TP53 Arg72Pro polymorphisms (all $P>0.05$ ). Furthermore, MDM2 and TP53 polymorphisms and their interaction were not associated with the low-risk or high- risk MDS according to FAB (RA and RARS versus RAEB and RAEBt), IPSS (Low-risk and Int- 1 versus Int-2 and high-risk) and cytogenetic risk (low-risk versus intermediate and high-risk) (Table 4).

Table 4. Effects of MDM2 and TP53 genotypes, or their interaction, in MDS, as stratified by disease risk groups

\begin{tabular}{|c|c|c|c|c|c|c|c|c|c|c|}
\hline \multicolumn{2}{|l|}{ Genotypes } & \multicolumn{2}{|c|}{$\operatorname{FAB}(n=77), n^{0}(\%)$} & & \multicolumn{2}{|c|}{ IPSS $(n=72), n^{0}(\%)$} & \multicolumn{4}{|c|}{$\begin{array}{l}\text { Karyotype category }(\mathrm{n}=73), \\
\mathrm{n}^{0}(\%)\end{array}$} \\
\hline MDM2 SNP309 & TP53 Arg72Pro & Low-risk & High-risk & & $\begin{array}{l}\text { Low and } \\
\text { INT-1 }\end{array}$ & $\begin{array}{l}\text { INT-2 and } \\
\text { high }\end{array}$ & & good & $\begin{array}{l}\text { Intermediate } \\
\text { and poor }\end{array}$ & \\
\hline MDM2 or TP53 & & & & $P^{*}$ & & & $P^{*}$ & & & $P^{*}$ \\
\hline $\mathrm{T} / \mathrm{T}$ & & $32(41.5)$ & $8(10.4)$ & & $31(43.1)$ & $7(9.7)$ & & $31(42.5)$ & $7(9.6)$ & \\
\hline $\mathrm{T} / \mathrm{G}$ & & $25(32.5)$ & $5(6.5)$ & 0.691 & $25(34.7)$ & $2(2.8)$ & 0.216 & $25(34.2)$ & $4(5.5)$ & 0.475 \\
\hline G/G & & $5(6.5)$ & $2(2.6)$ & & $5(6.9)$ & $2(2.8)$ & & $4(5.5)$ & $2(2.7)$ & \\
\hline \multirow[t]{5}{*}{ G alelle } & & $30(39.0)$ & $7(9.1)$ & 1.000 & 30 (41.6) & $4(5.6)$ & 0.522 & 29 (39.7) & $6(8.2)$ & 1.000 \\
\hline & Arg/Arg & $28(36.3)$ & $7(9.1)$ & & $28(38.9)$ & $5(6.9)$ & & $26(35.6)$ & $7(9.6)$ & \\
\hline & Arg/Pro & $29(37.7)$ & $7(9.1)$ & 1.000 & $28(38.9)$ & $5(6.9)$ & 1.000 & $30(41.1)$ & $5(6.8)$ & 0.717 \\
\hline & Pro/Pro & $5(6.5)$ & $1(1.3)$ & & $5(7.0)$ & $1(1.4)$ & & $4(5.5)$ & $1(1.4)$ & \\
\hline & Pro alelle & $34(44.2)$ & $8(10.4)$ & 1.000 & $33(45.9)$ & $6(8.3)$ & 1.000 & $34(46.6)$ & $6(8.2)$ & 0.549 \\
\hline \multicolumn{2}{|c|}{ Interaction of $M D M 2$ and TP53 } & & & $P \dagger$ & & & $P \dagger$ & & & $P \dagger$ \\
\hline \multirow[t]{3}{*}{$\mathrm{T} / \mathrm{T}$} & Arg/Arg & $16(20.7)$ & $3(3.9)$ & Ref. & $14(19.4)$ & $3(4.2)$ & Ref. & $13(17.8)$ & $4(5.5)$ & Ref. \\
\hline & Arg/Pro & $13(16.9)$ & $5(6.5)$ & 0.447 & $14(19.4)$ & $4(5.5)$ & 1.000 & $15(20.5)$ & $3(4.1)$ & 0.691 \\
\hline & Pro/Pro & $3(3.9)$ & $0(0.0)$ & 1.000 & $3(4.2)$ & $0(0.0)$ & 1.000 & $3(4.1)$ & $0(0.0)$ & 1.000 \\
\hline \multirow[t]{3}{*}{$\mathrm{T} / \mathrm{G}$} & Arg/Arg & $11(14.3)$ & $3(3.9)$ & 1.000 & $13(18.1)$ & $1(1.4)$ & 0.607 & $12(16.4)$ & $2(2.7)$ & 0.664 \\
\hline & Arg/Pro & $12(15.6)$ & $1(1.3)$ & 0.629 & $11(15.3)$ & $0(0.0)$ & 0.258 & $12(16.4)$ & $1(1.4)$ & 0.355 \\
\hline & Pro/Pro & $2(2.6)$ & $1(1.3)$ & 0.470 & $1(1.4)$ & $1(1.4)$ & 0.386 & $1(1.4)$ & $1(1.4)$ & 0.468 \\
\hline \multirow[t]{3}{*}{$\mathrm{G} / \mathrm{G}$} & Arg/Arg & $1(1.3)$ & $1(1.3)$ & 0.352 & $1(1.4)$ & $1(1.4)$ & 0.386 & $1(1.4)$ & $1(1.4)$ & 0.468 \\
\hline & Arg/Pro & $4(5.2)$ & $1(1.3)$ & 1.000 & $4(5.5)$ & $1(1.4)$ & 1.000 & $3(4.1)$ & $1(1.4)$ & 1.000 \\
\hline & Pro/Pro & $0(0.0)$ & $0(0.0)$ & & $0(0.0)$ & $0(0.0)$ & & $0(0.0)$ & $0(0.0)$ & \\
\hline
\end{tabular}

Abbreviations. FAB: French-American-British ; IPSS: International Prognostic Scoring System; INT-1: Intermediate-1; INT-2: Intermediate-2. ${ }^{*}$ Fisher's exact test; $†$ Chi-square test. 
MDM2 SPN309 and TP53 Arg72Pro were not associated with age of onset, disease progression and overall survival. The median ages of onset for MDM2 genotypes were 65.5 years (27.5-88.9) for $\mathrm{T} / \mathrm{T}, 61.1$ years (21.1-86.7) for $\mathrm{T} / \mathrm{G}$ and 61.0 years $(25.1-71.1)$ for G/G. For TP53 genotypes the median ages were 68.8 years (22.1-88.9) for Arg/Arg, 60.6 years (21.1-82.4) for Arg/Pro and 60.1 years (38.4-69.4) for Pro/Pro. Comparison of overall survival between patients according to MDM2 and TP53 polymorphisms revealed no significant difference $(P>0.05)$. The median survival based in MDM2 genotypes were 34.4 months (range, 164.5-2.2 months) for $\mathrm{T} / \mathrm{T}, 39.7$ months (range, 166.0-7.3 months) for T/G and 30.9 months (range, 88.1-4.1 months) for G/G. Based on TP53 genotypes the median survival were 38.9 months (range, 150.2-2.0 months) for Arg/Arg, 30.8 months (range, 166.0-2.2 months) for Arg/Pro and 46.9 months (range, 134.3-2.7 months) for Pro/Pro. Similarly, the interaction between MDM2 and TP53 polymorphisms did not affect overall survival $(P>0.05)$.

\section{Discussion}

Several studies have investigated the association between MDM2 and TP53 polymorphisms with risk of different cancers, including AML $[2,3,12]$, however, the results are inconclusive. The G allele of MDM2 SNP309 was associated with increased risk of AML, but no association was found between MDM2 or TP53 polymorphisms and age of onset or other clinical manifestations [12]. In contrast, in another study, the G allele was associated with a reduced risk of leukemia, and again no association was observed between these polymorphisms with clinical parameters [3]. Ellis et al [2] described an interaction of MDM2 SNP309 and TP53 Arg72Pro polymorphisms with disease susceptibility and responses to genotoxic therapy in therapy-related MDS/AML.

Mutation of TP53 plays an important role in the pathogenesis of MDS and studies involving the p53/MDM2 pathway have emerged, suggesting a relationship of p53 expression with risk and prognosis [13, 14]. However, TP53 Arg72Pro has rarely been addressed in MDS and MDM2 SNP309 has not been reported in this disease. Herein, we investigated the association of both polymorphisms and their interaction in de novo MDS for the first time. Our results showed no association of these polymorphisms with risk of MDS and clinical parameters, even when the polymorphisms were analyzed individually or combined. Interestingly, McGraw et al (Blood, ASH Annual Meeting Abstracts 2011;116:269) recently reported that TP53 Arg72Pro homozygous Pro/Pro genotype occurs with significantly greater frequency in del5q MDS, compared to both non-del5q MDS and healthy controls, and no correlation was found with clinical parameters in MDS $5 \mathrm{q}$ and non-del5q. Regarding patients with non-del5q, our results are in agreement with McGraw et al, as no correlations were found in either studies. Interestingly our cohort included only four patients with del5q, which showed a TP53 Arg72Pro homozygous Arg/Arg genotype.

In summary, in our study, MDM2 SNP309 and TP53 Arg72Pro were not significantly associated with the risk for MDS and with clinical variables, including clinical parameters such as FAB, IPSS, cytogenetic risk, age of onset, disease progression and overall survival.

Acknowledgments: The authors would like to thank Nicola Conran and Raquel S Foglio for English review, and Cleide A. Moreira Silva, Helymar C Machado and Roberto Zulli for Statistical analyses. The authors would also like to thank Tereza Salles for her valuable technical assistance. This work was supported by Conselho Nacional de Desenvolvimento Científico e Tecnológico $(\mathrm{CNPq})$ and Fundação de Amparo à Pesquisa do Estado de São Paulo (FAPESP).

\section{References}

[1] PIM D,BANKS L p53 polymorphic variants at codon 72 exert different effects on cell cycle progression. Int J Cancer 2004; 108: 196-9. http://dx.doi.org/10.1002/ijc.11548

[2] ELLIS N A, HUO D, YILDIZ O, WORRILLOW L J, BANERJEE M, et al. MDM2 SNP309 and TP53 Arg72Pro interact to alter therapy-related acute myeloid leukemia susceptibility. Blood 2008; 112: 741-9. http://dx.doi.org/10.1182/blood2007-11-126508

[3] PHANG B H, LINN Y C, LI H,SABAPATHY K MDM2 SNP309 G allele decreases risk but does not affect onset age or survival of Chinese leukaemia patients. Eur J Cancer 2008; 44: 760-6. http://dx.doi.org/10.1016/j.ejca.2008.02.007

[4] BOND G L, HU W, BOND E E, ROBINS H, LUTZKER S G, et al. A single nucleotide polymorphism in the MDM2 promoter attenuates the p53 tumor suppressor pathway and accelerates tumor formation in humans. Cell 2004; 119: 591-602. http:// dx.doi.org/10.1016/j.cell.2004.11.022

[5] KADERI M A, MANSOURI M, ZAINUDDIN N, CAHILL N, GUNNARSSON R, et al. Lack of association between the MDM2 promoter polymorphism SNP309 and clinical outcome in chronic lymphocytic leukemia. Leuk Res 2009; 34: 335-9. http://dx.doi.org/10.1016/j.leukres.2009.06.006

[6] DUMONT P, LEU J I, DELLA PIETRA A C, 3RD, GEORGE D L,MURPHY M The codon 72 polymorphic variants of $\mathrm{p} 53$ have markedly different apoptotic potential. Nat Genet 2003; 33: 357-65. http://dx.doi.org/10.1038/ng1093

[7] LIST A F, VARDIMAN J, ISSA J P,DEWITTE T M Myelodysplastic syndromes. Hematology Am Soc Hematol Educ Program 2004; 297-317. http://dx.doi.org/10.1182/asheducation-2004.1.297

[8] MORI N, HIDAI H, YOKOTA J, OKADA M, MOTOJI T, et al. Mutations of the p53 gene in myelodysplastic syndrome and overt leukemia. Leuk Res 1995; 19: 869-75. http://dx.doi. org/10.1016/0145-2126(95)00058-5

[9] FIDLER C, WATKINS F, BOWEN D T, LITTLEWOOD T J, WAINSCOAT J S, et al. NRAS, FLT3 and TP53 mutations in patients with myelodysplastic syndrome and a $\operatorname{del}(5 q)$. Haematologica 2004; 89: 865-6. 
[10] SHAFFER L G, SLOVAK M L, CAMPBELL L J,Editors. ICN 2009: an international system for human cytogenetic nomenclature. Basel: S. Karger, 2009.

[11] HIRATA H, HINODA Y, KIKUNO N, KAWAMOTO K, SUEHIRO Y, et al. MDM2 SNP309 polymorphism as risk factor for susceptibility and poor prognosis in renal cell carcinoma. Clin Cancer Res 2007; 13: 4123-9. http://dx.doi. org/10.1158/1078-0432.CCR-07-0609

[12] XIONG X, WANG M, WANG L, LIU J, ZHAO X, et al. Risk of MDM2 SNP309 alone or in combination with the p53 codon 72 polymorphism in acute myeloid leukemia.
Leuk Res 2009; 33: 1454-8. http://dx.doi.org/10.1016/ j.leukres.2009.04.007

[13] JADERSTEN M, SAFT L, SMITH A, KULASEKARARAJ A, POMPLUN S, et al. TP53 Mutations in Low-Risk Myelodysplastic Syndromes With del(5q) Predict Disease Progression. J Clin Oncol 2011; 29: 1971-9. http://dx.doi.org/10.1200/ LCO.2010.31.8576

[14] PELLAGATTI A, MARAFIOTI T, PATERSON J C, BARLOW $J$ L, DRYNAN L F, et al. Induction of p53 and up-regulation of the p53 pathway in the human 5q- syndrome. Blood 2010; 115: 2721-3. http://dx.doi.org/10.1182/blood-2009-12-259705 